\title{
Total Synthesis of Salimabromide: A Tetracyclic Polyketide from a Marine Myxobacterium
}

\author{
Matthias Schmid, ${ }^{\dagger,}$ Adriana S. Grossmann, ${ }^{\dagger}$ Klaus Wurst, ${ }^{\S}$ and Thomas Magauer ${ }^{*}, \oplus$ \\ ${ }^{\dagger}$ Department of Chemistry, Ludwig-Maximilians-University Munich, Butenandtstrasse 5-13, 81377 Munich, Germany \\ ${ }^{\ddagger}$ Institute of Organic Chemistry and Center for Molecular Biosciences, University of Innsbruck, Innrain 80-82, 6020 Innsbruck, \\ Austria \\ ${ }^{\S}$ Institute of General, Inorganic \& Theoretical Chemistry, University of Innsbruck, Innrain 80-82, 6020 Innsbruck, Austria
}

Supporting Information

ABSTRACT: Salimabromide is an antibiotic polyketide that was previously isolated from the obligate marine myxobacterium Enhygromyxa salina, and its densely functionalized and conformationally rigid tetracyclic framework is unprecedented in nature. Herein we report the first chemical synthesis of the target structure by employing a series of well-orchestrated, robust transformations, highlighted by an acid-promoted, powerful Wagner-Meerwein rearrangement/Friedel-Crafts cyclization sequence to forge the two adjacent quaternary carbon centers embedded in the tetrahydronaphthalene. A high-yielding ketiminium mediated $[2+2]$-cycloaddition was also utilized for the simultaneous construction of the remaining three stereocenters.

- yxobacteria of terrestrial origin produce an abundance 1 of structurally complex secondary metabolites with notable biological activities. Prominent examples include epothilone, corallopyronin and soraphen. ${ }^{1}$ Marine myxobacteria, on the other hand, have eluded their cultivation and isolation on many occasions and constitute a largely unexplored treasure trove of bioactive molecules. ${ }^{2}$ Haliangincin (2), which was reported in seminal work by Fudou in 2001, represents the first natural product isolated from a strictly marine myxobacterium (Scheme 1a). Following this early report, only a handful of new marine myxobacterium molecules have appeared in the literature, ${ }^{2}$ and in 2013, König disclosed the isolation of salimabromide $(\mathbf{1})$ in minute quantities $(0.5$ $\mathrm{mg}$ from $64 \mathrm{~L}$ of culture) from the obligate marine bacterium Enhygromxya salina. ${ }^{4}$ Although a broad biological screening campaign was impossible at this stage, 1 was shown to possess inhibitory activity against Arthrobacter crystallopoietes (16 $\mu \mathrm{g}$ $\mathrm{mL}^{-1}$ ).

From a structural point of view, salimabromide (1) contains an unprecedented tetracyclic ring-architecture that contains four consecutive stereocenters, one of which is quaternary. Additionally, the brominated tetrahydronaphthalene core is bridged at $\mathrm{C} 12$ and $\mathrm{C} 15$ to form a highly substituted and synthetically challenging seven-membered carbocycle. ${ }^{5}$ The conformational flexibility of this subunit is further reduced by fusion to a five-membered lactone.

The structure for $\mathbf{1}$ was exclusively deduced from extensive NMR measurements. Though this only confirmed the
Scheme 1. (a) Structural Diversity Produced by Marine Myxobacteria and (b) Key Retrosynthetic Bond Disconnections for Salimabromide (1)

a)

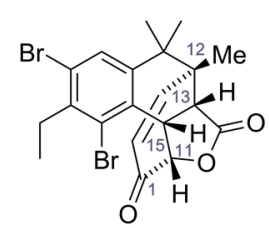

salimabromide (1) [2013, antibiotic]<smiles>CC(/C=C/[C@H](CO)C(C)(C)O)[C@H]1CC[C@H]2C3CC(=O)OC3=CC[C@]21C</smiles>

salimyxin (3)

[2013, antibiotic]<smiles>C=C[C@H]1O[C@]1(C)CC(C)/C(C)=C/C=C(C)/C=C(OC)/C(=C\C(=O)OC)OC</smiles>

haliangicin (2) [2001, antifungal]

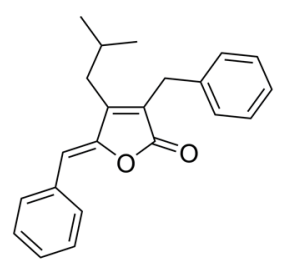

enhygrolide A (4) [2013, antibiotic] b)
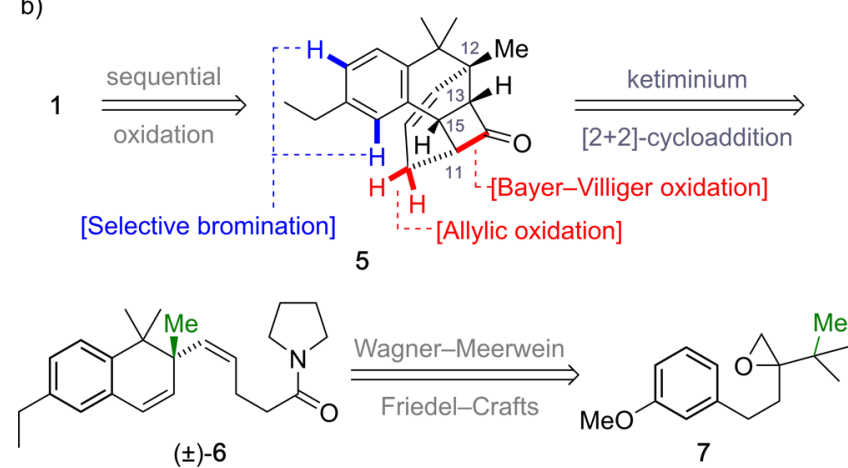

(士)-6

connectivity, the absolute stereochemistry was determined by comparison of calculated and measured CD spectra.

Despite considerable progress of the Menche group, ${ }^{5}$ no total synthesis of salimabromide (1) has been accomplished to date. In light of these considerations, we set out to develop a practical synthetic route to enable rapid access to 1 and fully

Received: June 13, 2018

Published: June 28, 2018 
synthetic derivatives thereof. Herein we describe a streamlined synthesis of 1 employing a series of robust chemical transformations. The successful realization of this route allowed us to produce $1.9 \mathrm{~g}$ of a highly advanced intermediate in a single batch from which salimabromide (1) was prepared in only three steps.

Our retrosynthetic bond disconnections were guided by our desire to rapidly generate molecular complexity and to install the individual stereocenters via a minimum number of synthetic operations (Scheme 1b). We planned to first install the pivotal $\mathrm{C} 12$ quaternary carbon center and utilize this handle for the subsequent one-step construction of the stereotriad along $\mathrm{C} 11, \mathrm{C} 13$ and $\mathrm{C} 15$. For this purpose and in analogy to the logic of two-phase terpene (bio)synthesis, salimabromide (1) was first reduced to tetracycle 5. This intermediate was designed to eliminate steric hindrance and cross-reactivity of the bromine substituents en route to the tetracyclic carbon framework of $\mathbf{1}$. Compound 5 contains the retron for a powerful ketiminium mediated $[2+2]$-cycloaddition $^{7}$ to produce the simplified dihydronaphthalene 6 . Further $\mathrm{C}-\mathrm{C}$ bond disconnections involving truncation of the side chain and a retro-Friedel-Crafts cyclization/WagnerMeerwein ${ }^{8}$ rearrangement sequence provided epoxide 7.

We commenced our synthesis with the Claisen-Schmidt condensation of commercially available 3-methoxybenzaldehyde 8 with pinacolone 9 (Scheme 2). Though slow reactions

Scheme 2. Synthesis of the Tetrahydronaphthalene Framework via Consecutive Wagner-Meerwein Rearrangement and Friedel-Crafts Cyclization
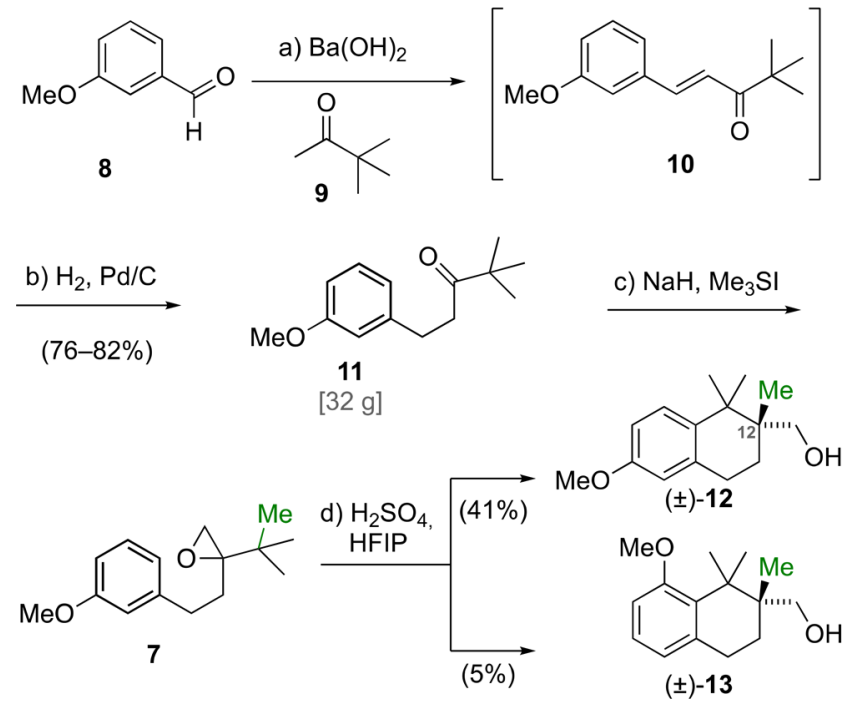

${ }^{a}$ Reagents and conditions: (a) $\left[\mathrm{Ba}(\mathrm{OH})_{2} \cdot \mathrm{H}_{2} \mathrm{O}, \mathrm{C}-200\right]$, pinacolone 9, EtOH, $78{ }^{\circ} \mathrm{C}$; (b) Pd/C, $\mathrm{H}_{2}$, EtOAc, $23{ }^{\circ} \mathrm{C}, 76-82 \%$ over two steps; (c) $\mathrm{NaH}, \mathrm{DMSO}, 70{ }^{\circ} \mathrm{C}$, then $\mathrm{Me}_{3} \mathrm{SI}, 0$ to $23{ }^{\circ} \mathrm{C}$; (d) $\mathrm{H}_{2} \mathrm{SO}_{4}$, HFIP, $23{ }^{\circ} \mathrm{C}, 41 \%$ for $12,5 \%$ for 13 over two steps.

(48 h) and moderate yields (48\%) were observed for standard bases such as sodium or potassium hydroxide, the use of activated barium hydroxide $\left[\mathrm{Ba}(\mathrm{OH})_{2} \cdot \mathrm{H}_{2} \mathrm{O}, \mathrm{C}-200\right]^{9}$ led to rapid consumption of the reactants and clean conversion to the condensation product 10. On large scale, 10 was best obtained by simple filtration of the reaction mixture using a pad of Celite and evaporation of excess ethanol and pinacolone 9. The following heterogeneous hydrogenation $\left(1 \mathrm{~atm} \mathrm{H}_{2}, \mathrm{Pd} / \mathrm{C}\right.$, EtOAc) was conducted on large-scale and reproducibly provided 11 in good yield (76-83\% over two steps, $32 \mathrm{~g}$ ). Exposure of 11 to standard Corey-Chaykovsky conditions ( NaDMSO, $\mathrm{Me}_{3} \mathrm{SI}, 0$ to $\left.23{ }^{\circ} \mathrm{C}\right)^{10}$ effected clean conversion to epoxide 7 . With 7 in hand, we investigated the crucial rearrangement-cyclization sequence. We found that exposure of 7 to hexanes/sulfuric acid or dichloromethane/titanium(IV) chloride was low-yielding for $12(\sim 30 \%)$ and afforded substantial amounts of the undesired ortho-product 13 ( $\sim 10 \%)$. Further screening revealed 1,1,1,3,3,3-hexafluoro-2propanol (HFIP, $0.1 \mathrm{M}$ ), a strong hydrogen-bond donor and weak nucleophile, ${ }^{11}$ as the solvent of choice and concentrated sulfuric acid as the optimal catalyst $(10 \mathrm{~mol} \%)$. Under these conditions, the para-product $\mathbf{1 2}$ was formed with very good regioselectivity $(12: 13=8: 1)$. The remainder of the mass balance corresponds to a complex mixture of byproducts. ${ }^{12}$ Similar results were obtained when the reaction was conducted in a hexameric resorcinarene capsule. ${ }^{13}$ In agreement with related Lewis-acid catalyzed semipinacol and WagnerMeerwein rearrangements, ${ }^{14}$ a high level of stereoselectivity should be possible for the initial rearrangement step. Evidence was obtained when a solution of enantiomerically enriched 7 ( $82 \%$ ee) in dichloromethane was exposed to titanium(IV) chloride at $-78{ }^{\circ} \mathrm{C}$. Under these conditions, an enantiomeric excess of $70 \%$ was obtained for 12 (see Supporting Information for details). This result provides an opportunity to access $\mathbf{1}$ in an asymmetric fashion.

Having successfully installed the crucial C12 quaternary stereocenter in only four steps, we turned our attention to the remaining functionalization of $\mathbf{1 2}$ (Scheme 3). To begin, the primary alcohol was protected as its tert-butyldiphenylsilyl (TBDPS) ether, and styrene $\mathbf{1 4}$ was then formed via exposure to 2,3-dichloro-5,6-dicyano-1,4-benzoquinone (DDQ 2 equiv). ${ }^{15}$ The use of substochiometric amounts of DDQ (30 mol \%) in combination with manganese(IV) oxide (6 equiv) or alternative oxidation agents such as chloranil, $\mathrm{Pd} / \mathrm{C}$ or electrochemical methods (4 V, chloranil, $\mathrm{Pt} / \mathrm{Pt}, 0.1 \mathrm{M} \mathrm{LiClO}_{4}$, $\mathrm{MeCN}$ ) were ineffective.

The TBDPS group was crucial for the stability of the silyl ether under the reaction conditions, and the presence of the electron-donating methoxy substituent was beneficial for the oxidation. $^{16}$

For the installation of the missing ethyl substituent, we initially investigated the direct coupling of $\mathbf{1 4}$ using nickel (e.g., $\mathrm{Ni}(\text { acac })_{2}$, dcype, EtMgBr, $\mathrm{MgI}_{2}, \mathrm{PhMe}, 100{ }^{\circ} \mathrm{C}$; $\mathrm{Ni}(\operatorname{cod})_{2}$, dcype, EtMgI, $\mathrm{MgI}_{2}$, PhMe, $\left.100{ }^{\circ} \mathrm{C}\right) .{ }^{17}$ Because our substrate proved to be remarkably unreactive under these conditions, we decided to replace the methoxy substituent with a more reactive triflate. For the removal of the methyl ether, freshly prepared lithium diphenylphosphide $\left(\mathrm{Ph}_{2} \mathrm{PH}, n\right.$-BuLi) was found to be optimal. ${ }^{18}$ The free phenol was then converted to the triflate upon exposure to the Hendrickson-McMurray reagent $\left(\mathrm{PhNTf}_{2}\right)^{19}$ to afford $\mathbf{1 5}$ in quantitative yield. Standard Negishi cross-coupling $\left(\mathrm{Pd}(\mathrm{dppf}) \mathrm{Cl}_{2}, \mathrm{ZnEt}_{2} \text {, dioxane, } 70{ }^{\circ} \mathrm{C}\right)^{20}$ enabled clean installation of the missing ethyl substituent (92\%), and cleavage of the silyl ether (TBAF, THF, $23{ }^{\circ} \mathrm{C}$ ) gave alcohol 16 (99\%). The remaining carbon-chain was introduced in a three-step sequence beginning with the oxidation of 16 using Dess-Martin periodinane ${ }^{21}$ (96\%), followed by a high-yielding, $Z$-selective Wittig olefination and amide formation (pyrrolidine, $100{ }^{\circ} \mathrm{C}$ ) to provide $6(85 \%)$.

With robust access to the dihydronaphthalene 6 , we proceeded to investigate the key-step of our synthesis: a ketiminium ion mediated $[2+2]$-cycloaddition ${ }^{7}$ to construct 
Scheme 3. Total Synthesis of Salimabromide ${ }^{a}$<smiles>COc1ccc2c(c1)CC[C@](C)(CO)C2(C)C</smiles>

12

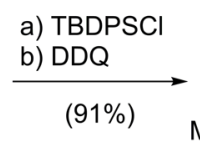

g) DMP

h) $\mathrm{CtO}^{\mathrm{O}} 17 \mathrm{PPh}_{3} \mathrm{Br}$<smiles>CCc1ccc2c(c1)C=CC(C)(CO)C2(C)C</smiles>

i) pyrrolidine $\longrightarrow$

$(81 \%)$

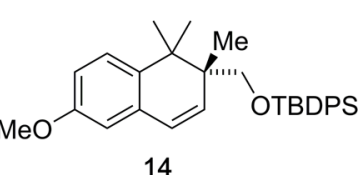

14

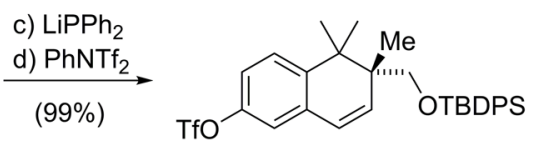

15 e) $\mathrm{ZnEt}_{2}, \mathrm{Pd}(\mathrm{dppf}) \mathrm{Cl}_{2}$ f) TBAF

$(91 \%)$

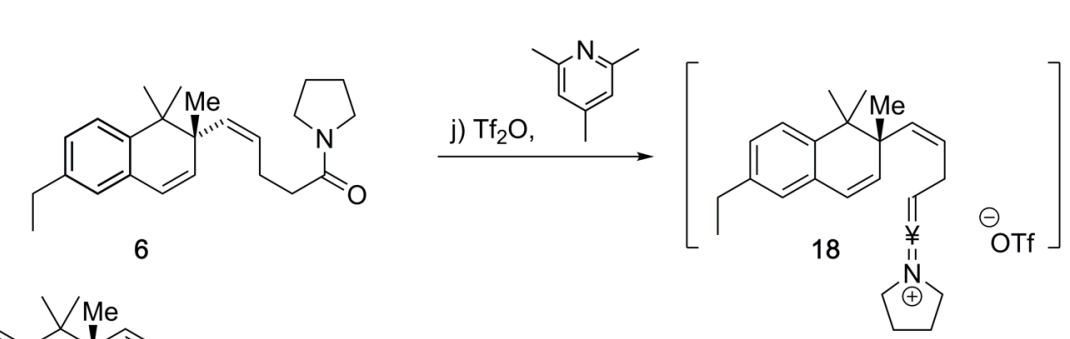

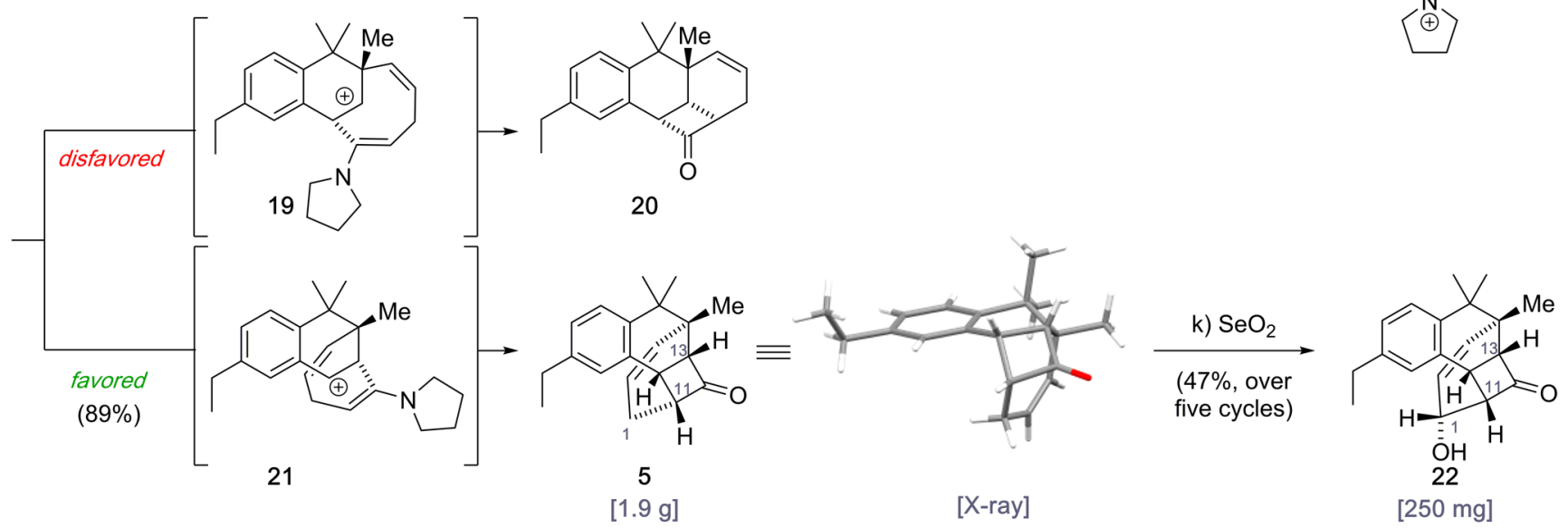

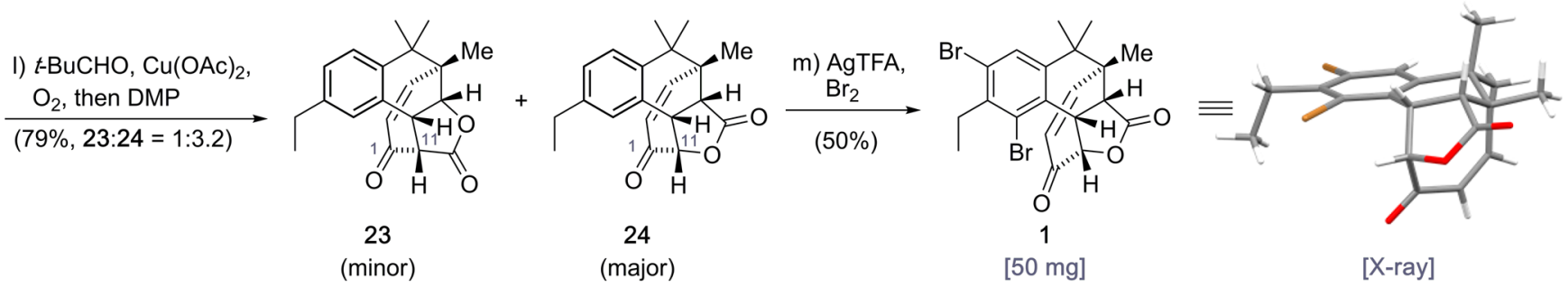

${ }^{a}$ Reagents and conditions: (a) TBDPSCl, imidazole, DMAP, DMF, $23{ }^{\circ} \mathrm{C}$; (b) DDQ dioxane, $93{ }^{\circ} \mathrm{C}, 91 \%$ over two steps; (c) LiPPh 2 , THF, 60 ${ }^{\circ} \mathrm{C}$; (d) $\mathrm{PhNTf}_{2}, \mathrm{NEt}_{3}$, THF, $23{ }^{\circ} \mathrm{C}$, 99\% over two steps; (e) $\mathrm{ZnEt}_{2}, \mathrm{Pd}(\mathrm{dppf}) \mathrm{Cl}_{2}$, dioxane, $70{ }^{\circ} \mathrm{C}$, 92\%; (f) TBAF, THF, $23{ }^{\circ} \mathrm{C}, 99 \%$; (g) DMP, $\mathrm{K}_{2} \mathrm{CO}_{3}, \mathrm{CH}_{2} \mathrm{Cl}_{2}, 0$ to $23{ }^{\circ} \mathrm{C}$, 96\%; (h) NaHMDS, 17, THF, -78 to $+23{ }^{\circ} \mathrm{C}$, 85\%; (i) pyrrolidine, $100{ }^{\circ} \mathrm{C}, 99 \%$; (j) $\mathrm{Tf}_{2} \mathrm{O}, 2,4,6$-collidine, $\mathrm{ClCH}_{2} \mathrm{CH}_{2} \mathrm{Cl}, 80^{\circ} \mathrm{C}, 89 \%$; (k) $\mathrm{SeO}_{2}, \mathrm{SiO}_{2}$, dioxane, $120{ }^{\circ} \mathrm{C}$, $47 \%$ over five cycles; (l) $t$ - $\mathrm{BuCHO}, \mathrm{Cu}(\mathrm{OAc}){ }_{2}, \mathrm{O}_{2}(1 \mathrm{~atm}), \mathrm{ClCH}_{2} \mathrm{CH}_{2} \mathrm{Cl}_{2} 2{ }^{\circ} \mathrm{C}$, then DMP, $\mathrm{NaHCO}_{3}, \mathrm{CH}_{2} \mathrm{Cl}_{2}, 79 \%, 23: 24=1: 3.2 ;$ (m) AgTFA, $\mathrm{Br}_{2}, \mathrm{CF}_{3} \mathrm{COOH}, 50 \%$.

the seven-membered carbocycle and complete the tetracyclic carbon framework. Under optimized conditions, a solution of amide 6 and sym-collidine (1.2 equiv) in dichloroethane was slowly added to a refluxing solution of freshly distilled trifluoromethanesulfonic anhydride (1.2 equiv) in dichloroethane $(0.1 \mathrm{M})$. The cycloaddition produced the tetracycle 5 with almost perfect regio- and diastereoselectivity in excellent yield $(89 \%, 1.9 \mathrm{~g})$. The exact mechanism, concerted (synchronous/asynchronous) or stepwise, has been a matter of debate for many decades. ${ }^{7}$ Depending on the substitution pattern on both the alkene and the ketiminium salt, either of the two pathways might be operational. ${ }^{22}$ The greater resonance stabilization of the benzylic cation 21 versus 19 was envisioned to govern the regioselectivity favoring formation of $\mathbf{5}$.

Having installed the crucial stereocenters, we were poised to tackle the remaining challenges: regioselective oxidation of the carbon-framework and bromination of the arene subunit.
When $5(500 \mathrm{mg})$ was treated with selenium dioxide (dioxane, $120{ }^{\circ} \mathrm{C}, 6 \mathrm{~h}$ ) in the presence of silicon dioxide (>230 mesh) to prevent agglomeration, the diastereomerically pure allylic alcohol 22 was formed together with unreacted 5. Extended reaction times were detrimental as overoxidation and decomposition started to prevail. Subjection of recovered 5 (76\%) to the reaction conditions enabled us to prepare $250 \mathrm{mg}$ of 22 after five cycles $\left(47 \%, \sim 15 \%\right.$ for the first cycle). ${ }^{23}$ Subsequent Baeyer-Villiger oxidation using standard conditions ( $m$-CPBA, $\mathrm{NaHCO}_{3}, \mathrm{CH}_{2} \mathrm{Cl}_{2}$ ) gave two regioisomeric lactones, which were directly oxidized (DMP, $\mathrm{NaHCO}_{3}$, $\mathrm{CH}_{2} \mathrm{Cl}_{2}$ ) to afford 23 and 24 in a ratio of $1.4: 1$ in $84 \%$ combined yield. Separation of 23 and 24 was readily accomplished by flash column chromatography. To improve this undesired outcome, further optimization of the oxidant was performed. Interestingly, exposure of 22 to $t$ - $\mathrm{BuCHO}$ ( 5 equiv) in the presence of molecular oxygen ( $1 \mathrm{~atm})$ and copper(II) acetate ( 1 equiv) gave 24 as the major product 
(79\%, 23:24 $=1: 3.2){ }^{24}$ The directing effect of the free hydroxy group was crucial as the corresponding methyl ether led to lower regioselectivity $(1: 1.1)$ only slightly favoring the desired regioisomer (compare 24). It is also noteworthy that replacement of $t$-BuCHO with $m$-CPBA in the Baeyer-Villiger step under otherwise identical conditions was even less efficient and only poor regioselectivity $(23: 24=1.2: 1)$ was obtained. For the introduction of the missing bromine substituents, 24 was exposed to a panel of brominating agents (e.g., $\mathrm{Br}_{2}, \mathrm{CHCl}_{3}$; NBS, $\mathrm{HOAc} ; \mathrm{BnMe}_{3} \mathrm{NBr}_{3}, \mathrm{ZnBr}_{2}, \mathrm{HOAc}$ ). Under these conditions, formation of $\mathbf{1}$ was only observed in trace amounts if at all. Finally, we found that treating a solution of 24 in trifluoroacetic acid $(0.1 \mathrm{M})$ with silver(I) trifluoroacetate (3 equiv) and elemental bromine (3 equiv) enabled the desired bromination (50\%) and thus completed the synthesis of salimabromide $(1,50 \mathrm{mg}){ }^{25}$ The analytical data for $\mathbf{1}\left({ }^{1} \mathrm{H}\right.$ NMR, ${ }^{13} \mathrm{C}$ NMR, HRMS) fully matched those reported for the natural compound. Additionally, the structure of $\mathbf{1}$ was unambiguously validated by single-crystal X-ray diffraction analysis.

In summary, we have completed the first total synthesis of salimabromide, a unique tetracyclic polyketide. The highlights of the developed route are (1) a powerful Wagner-Meerwein rearrangement/Friedel-Crafts cyclization sequence to forge the tetrahydronaphthalene skeleton and (2) a high-yielding ketiminium mediated $(2+2)$-cycloaddition to set the remaining three stereocenters. The overall sequence benefits from a series of practical transformations that can be also conducted on large scale. The robustness of the developed synthesis is evident from the fact that more than $1.9 \mathrm{~g}$ of a highly advanced intermediate were prepared in a single batch.

\section{ASSOCIATED CONTENT}

\section{S Supporting Information}

The Supporting Information is available free of charge on the ACS Publications website at DOI: 10.1021/jacs.8b06228.

Experimental details and spectroscopic data (PDF) X-ray crystallographic data for 1, 5, 23 and 24 (CIF)

\section{AUTHOR INFORMATION}

\section{Corresponding Author}

*thomas.magauer@uibk.ac.at

\section{ORCID $\odot$}

Thomas Magauer: 0000-0003-1290-9556

\section{Notes}

The authors declare no competing financial interest.

\section{ACKNOWLEDGMENTS}

T.M. acknowledges the European Research Council under the European Union's Horizon 2020 research and innovation program (grant agreement no. 714049) and the Center for Molecular Biosciences (CMBI). M.S. gratefully acknowledges financial support from the German National Academic Foundation. We thank Dr. Kevin Mellem (Revolution Medicines) for helpful discussions, Prof. Albrecht Berkessel (University of Cologne) for a screen of epoxidation catalysts and Prof. Konrad Tiefenbacher (University of Basel/ETH) for the screen of supramolecular catalysts.

\section{REFERENCES}

(1) Herrmann, J.; Fayad, A. A.; Müller, R. Nat. Prod. Rep. 2017, 34, 135.
(2) (a) Dávila-Céspedes, A.; Hufendiek, P.; Crüsemann, M.; Schäberle, T. F.; König, G. M. Beilstein J. Org. Chem. 2016, 12, 969. (b) Felder, S.; Kehraus, S.; Neu, E.; Bierbaum, G.; Schäberle, T. F.; König, G. M. ChemBioChem 2013, 14, 1363.

(3) Fudou, R.; Iizuka, T.; Sato, S.; Ando, T.; Shimba, N.; Yamanaka, S. J. Antibiot. 2001, 54, 153.

(4) Felder, S.; Dreisigacker, S.; Kehraus, S.; Neu, E.; Bierbaum, G.; Wright, P. R.; Menche, D.; Schäberle, T. F.; König, G. M. Chem. - Eur. J. 2013, 19, 9319.

(5) Schmalzbauer, B.; Menche, D. Org. Lett. 2015, 17, 2956.

(6) Chen, K.; Baran, P. S. Nature 2009, 459, 824.

(7) (a) Snider, B. B. Chem. Rev. 1988, 88, 793. (b) Madelaine, C.; Valerio, V.; Maulide, N. Chem. - Asian J. 2011, 6, 2224.

(8) (a) Knölker, H.-J.; Baum, E.; Graf, R.; Jones, P. G.; Spieß, O. Angew. Chem., Int. Ed. 1999, 38, 2583. (b) Khalaf, A. A.; Albar, H. A.; El-Fouty, K. O. Indian J. Chem. 2010, 49B, 203.

(9) Sinisterra, J. V.; Garcia-Raso, A.; Cabello, J. A.; Marinas, J. M. Synthesis 1984, 1984, 502.

(10) Corey, E. J.; Chaykovsky, M. J. Am. Chem. Soc. 1965, 87, 1353.

(11) Bégué, J.-P.; Bonnet-Delpon, D.; Crousse, B. Synlett 2004, 1, 18.

(12) The mixture of byproducts could not be separated; however, careful analysis of the ${ }^{1} \mathrm{H}$ NMR revealed minor traces of the Meinwald rearrangement product. Meinwald, J.; Labana, S. S.; Chadha, M. S. J. Am. Chem. Soc. 1963, 85, 582. An Indane, resulting from the direct Friedel-Crafts reaction, was not detected.

(13) Zhang, Q.; Tiefenbacher, K. J. Am. Chem. Soc. 2013, 135, 16213.

(14) (a) Cram, D. J. J. Am. Chem. Soc. 1949, 71, 3863. (b) Suzuki, K.; Katayama, E.; Tsuchihashi, G. Tetrahedron Lett. 1984, 25, 1817. (c) Maruoka, K.; Hasegawa, M.; Yamamoto, H.; Suzuki, K.; Shimazaki, M.; Tsuchihashi, G. J. Am. Chem. Soc. 1986, 108, 3827. (d) Matsubara, S.; Yamamoto, H.; Oshima, K. Angew. Chem., Int. Ed. 2002, 41, 2837.

(15) Trost, B. M. J. Am. Chem. Soc. 1967, 89, 1847.

(16) Replacement of the methoxy with a triflate group gave low yields in the subsequent oxidation.

(17) Tobisu, M.; Takahira, T.; Morioka, T.; Chatani, N. J. Am. Chem. Soc. 2016, 138, 6711.

(18) (a) Mann, F. G.; Pragnell, M. J. J. Chem. Soc. 1965, 4120. (b) Ireland, R. E.; Welch, S. J. Am. Chem. Soc. 1970, 92, 7232.

(19) (a) Hendrickson, J. B.; Bergeron, R. Tetrahedron Lett. 1973, 14, 4607. (b) Mc Murry, J. E.; Scott, W. J. Tetrahedron Lett. 1983, 24, 979.

(20) (a) Hayashi, T.; Konishi, M.; Kobori, Y.; Kumada, M.; Higuchi, T.; Hirotsu, K. J. Am. Chem. Soc. 1984, 106, 158. (b) Negishi, E. Acc. Chem. Res. 1982, 15, 340.

(21) Dess, D. B.; Martin, J. C. J. Am. Chem. Soc. 1991, 113, 7277.

(22) Ding, W. J.; Fang, D.-C. J. Org. Chem. 2001, 66, 6673.

(23) For an alternative Schönecker $\mathrm{C}-\mathrm{H}$ oxidation, see Supplementary Information and see See, Y. Y.; Herrmann, A. T.; Aihara, Y.; Baran, P. S. J. Am. Chem. Soc. 2015, 137, 13776.

(24) (a) Bolm, C.; Schlingloff, G.; Weickhardt, K. Tetrahedron Lett. 1993, 34, 3405. (b) Bolm, C.; Schlingloff, G.; Weickhardt, K. Tetrahedron Lett. 1993, 34, 3405.

(25) (a) Haszeldine, R. N. J. Chem. Soc. 1951, 584. (b) Haszeldine, R. N.; Sharpe, A. G. J. Chem. Soc. 1952, 993. 